\title{
A SUPER ASPERITY MODEL FOR THE 2011 OFF THE PACIFIC COAST OF TOHOKU EARTHQUAKE
}

\author{
Atsushi NOZU ${ }^{1}$ \\ ${ }^{1}$ Member of JAEE, Head of Engineering Seismology Division, Port and Airport Research Institute, \\ Yokosuka, Japan,nozu@pari.go.jp
}

\begin{abstract}
This presents a newly developed source model, composed of super asperities, for the 2011 off the Pacific coast of Tohoku, Japan, earthquake. Strong ground motions were simulated based on site amplification and phase characteristics. The constructed source model involves 9 super asperities, located off the coast of Miyagi through Ibaraki. There was good agreement between the observed and calculated ground motions, especially for the velocity waveforms $(0.2-1.0 \mathrm{~Hz})$ including near-source pulses.
\end{abstract}

Key Words: the 2011 off the Pacific coast of Tohoku earthquake, strong ground motion, super asperity

\section{INTRODUCTION}

The 2011 off the Pacific coast of Tohoku, Japan, earthquake (hereafter referred to as "the Tohoku earthquake") was the first M9 class earthquake to be recorded by dense strong motion networks such as K-NET, etc ${ }^{12)}$. The occurrence of the earthquake enabled us to analyze actual strong ground motions resulting from an M9 class earthquake for the first time in history. At the same time, the occurrence of the Tohoku earthquake along the Japan Trench motivated us to hypothesize equally large earthquakes along other plate boundaries close to the coast of Japan, including the Nankai Trough. The evaluation of strong ground motions for such earthquakes should be based on a source model whose applicability to large earthquakes has been validated using existing strong motion records, including those from the Tohoku earthquake. In particular, if the evaluation of strong ground motions is aimed at the seismic design of structures, the applicability of the source model should be tested, especially over the frequency range from 0.2 to $1 \mathrm{~Hz}$, because strong ground motions in this frequency range have significant effects on a wide range of engineered structures including port structures ${ }^{3)}$.

Before the occurrence of the Tohoku earthquake, the author pointed out that a large amplitude $\mathrm{S}$-wave pulse from the source can predominate over the frequency range from 0.2 to $1 \mathrm{~Hz}$, not only for a shallow crustal earthquake but also for a huge subduction earthquake and identified two requirements for a model that predicts strong ground motions for a huge subduction earthquake ${ }^{3)}$ : (1) It should be capable of reproducing S-wave pulses which appear at sites without complicated site effects. (2) It should be capable of taking into account site-specific amplification and site-specific phase characteristics to reproduce site-dependent waveforms such as pulse-like waveforms or waveforms with significant later phases. To achieve this goal, the author proposed the following for the evaluation 
of strong ground motions of a huge subduction earthquake $\mathrm{e}^{344)}$ :

1) Use a source model composed of relatively small subevents, which is in agreement with the time-width of observed S-wave pulses in previous earthquakes.

2) Calculate strong ground motions based on site amplification and phase characteristics ${ }^{4) 566)}$.

In previous studies, the applicability of the above strategy to M8 class earthquakes was fully investigated $^{4) 6}$. In the present study, to investigate the applicability of the strategy to an M9 earthquake, a new source model with small subevents was developed for the 2011 Tohoku earthquake, and simulation of strong ground motions was conducted, based on the source model.

To construct the source model, an iterative forward modeling approach was used. Records from K-NET, KiK-net and Strong Motion Earthquake Observation in Japanese Ports ${ }^{7)}$ were used. The primary target was the velocity waveforms over the frequency range of $0.2-1 \mathrm{~Hz}$ (including S-wave pulses) and the secondary target was the Fourier spectra over the frequency range of $0.2-10 \mathrm{~Hz}$. Because an iterative forward modeling approach was used, the uniqueness of the result was not warranted. The process toward the final result, however, was more or less inevitable as explained in the following sections.

The subevents used in this study are referred to as "super asperities". The term "super asperity" was originally used by Matsushima and Kawase ${ }^{8)}$, who proposed to use a small subevent, approximately $4 \mathrm{~km}$ long, to explain the amplitude and time width of the S-wave pulse observed at the Kaihoku Bridge during the 1978 off Miyagi Prefecture earthquake $\left(M_{w} 7.6\right)$. Because their subevent was much smaller than the "asperities" conventionally assumed for a subduction earthquake of this size, they regarded the subevent as expressing heterogeneity inside the asperity, rather than corresponding to the asperity itself. Thus, they called the subevent a "super asperity". In their view, the source model was composed of three layers, namely, the super asperity, the asperity and the background region.

The subevents for the Tohoku earthquake employed in this study are also of the order of several kilometers long and are much smaller than the "asperities" that would conventionally be assumed for an M9 earthquake (several tens of kilometers long). Additionally, the subevents in this study are also aimed at reproducing the S-wave pulses, as was the subevent assumed by Matsushima and Kawase ${ }^{8)}$. Thus, the subevents in this study are referred to as "super asperities". Currently, however, the author is not in favor of the idea that the Tohoku earthquake involved asperities of several tens of kilometers. Consequently, the author is not in favor of the idea that the super asperity is an expression of heterogeneity inside the asperity, at least for the moment. The author even suspect that the super asperity may correspond to a locked region in the inter-seismic period. Thus, the author's interpretation of the super asperity is not necessarily the same as that of Matsushima and Kawase, although the two articles use the same terminology.

On the other hand, the term "SMGA" was also recently used to represent a subevent that generated strong ground motions on the fault ${ }^{9)}$. However, the author has intentionally avoided using this term, because the term "SMGA" often represents a region on the fault that generates random high-frequency components. On the contrary, this study is intended to reveal a region on the fault that generates a coherent pulse (in the frequency range relevant to structural damage). Therefore, it is not appropriate to refer to the subevents in this study as "SMGAs".

\section{METHOD USED TO CALCULATE STRONG GROUND MOTIONS}

For any candidate source model, strong ground motions were calculated based on site amplification and phase characteristics ${ }^{45) 6}$, which can take into account the effect of sediments for both the Fourier amplitude and phase of strong ground motions. An outline of the method follows.

The first step was to evaluate ground motions from a small event (Green's function). The Fourier amplitude of the Green's function was evaluated as a product of the source spectrum $|S(f)|$, the path effect $|P(f)|$ and the site amplification factor $|G(f)|$. The source spectrum was assumed to follow the $\omega^{-2}$ model ${ }^{10)}$. Geometrical spreading and non-elastic attenuation were considered for the path effect ${ }^{11)}$. The empirical site amplification factor was used for the site amplification factor. The Fourier phase of an 
actual record of a small earthquake at the site of interest was used for the Fourier phase of the Green's function. Thus, we obtained a time domain Green's function which incorporated the effects of sediments both for the Fourier amplitude and Fourier phase. Green's function in the frequency domain can be written as follows:

$$
|S(f)||P(f)||G(f)| O_{\mathrm{s}}(f) /\left|O_{\mathrm{s}}(f)\right|_{\mathrm{p}},
$$

where $O_{\mathrm{s}}(f)$ is the Fourier transform of an actual record at the site of interest and $\left|O_{\mathrm{s}}(f)\right|_{\mathrm{p}}$ is its Parzen-windowed amplitude (a band width of $0.05 \mathrm{~Hz}$ was used). If several records were available for the site, it was preferable to choose an event that had a similar incident angle and a similar back-azimuth to the target event.

The second step was to superpose Green's functions to obtain strong ground motions from a large event (or a subevent of a large event) in the same way as the EGF method ${ }^{9)}$. The resultant synthetic ground motions basically follow the $\omega^{-2}$ model.

For the particular application to the Tohoku earthquake, the averaged radiation coefficient of 0.63 was used. The parameter PRTITN ${ }^{11)}$, which represents the partition of S-wave energy into two horizontal components, was determined to be compatible with the observed records. For the S-wave velocity and the density in the source region, $3.9 \mathrm{~km} / \mathrm{s}$ and $3.1 \times 10^{3} \mathrm{~kg} / \mathrm{m}^{3}$ were used ${ }^{12) 13)}$. For the path effect, the $Q$ value estimated for the region ${ }^{14)}$ was used.

For the site amplification factors, the empirical site amplification factors obtained in Nozu and Nagao ${ }^{15)}$ were used, except for the two sites, MYG011 and Onahama-ji-GB (Fig. 1). The site MYG011 was relocated on January 30, 2004, and the site amplification factor for MYG011 in Nozu and Nagao $^{15)}$ corresponded to MYG011 before relocation. Therefore, the site amplification factor corresponding to MYG011 after relocation was newly evaluated empirically ${ }^{16)}$ and used in this study. The site amplification factor for Onahama-ji-GB, which was not included in Nozu and Nagao ${ }^{15}$, was also newly evaluated empirically ${ }^{16)}$ and used in this study. At the KiK-net stations, surface records rather than borehole records were used, because the site amplification factors obtained in Nozu and Nagao ${ }^{15)}$ corresponded to surface records.

The small events listed in Table 1 were used to determine the Fourier phase of the Green's functions. These events were selected taking into account the similarity of the incident angle and the back-azimuth between the small events and the super asperities. Major small events are plotted in Fig. 1.

At sites where the effect of soil nonlinearity was anticipated, the Green's functions were corrected for multiple nonlinear effects based on the simplified formula proposed by Nozu and Morikawa ${ }^{17}$. In this method, two parameters are used to represent soil nonlinearity: $v_{1}$, which corresponds to the averaged reduction of S-wave velocity within the sediment and $v_{2}$, which corresponds to the averaged increase of the damping factor within the sediment. If the following conditions were met, the correction was applied.

1) The soil profile indicated that the records could potentially be affected by soil nonlinearity.

2) The peak frequency of the main shock Fourier spectrum was apparently lower than that of the site amplification factor.

In this case, $v_{1}$ was determined based on the ratio of the peak frequency of the main shock Fourier spectrum with respect to that of the site amplification factor. On the other hand, $v_{2}$ was determined so that the duration of the later phases was appropriately reproduced. The selected values for $v_{1}$ and $v_{2}$ are listed in Table 2. 


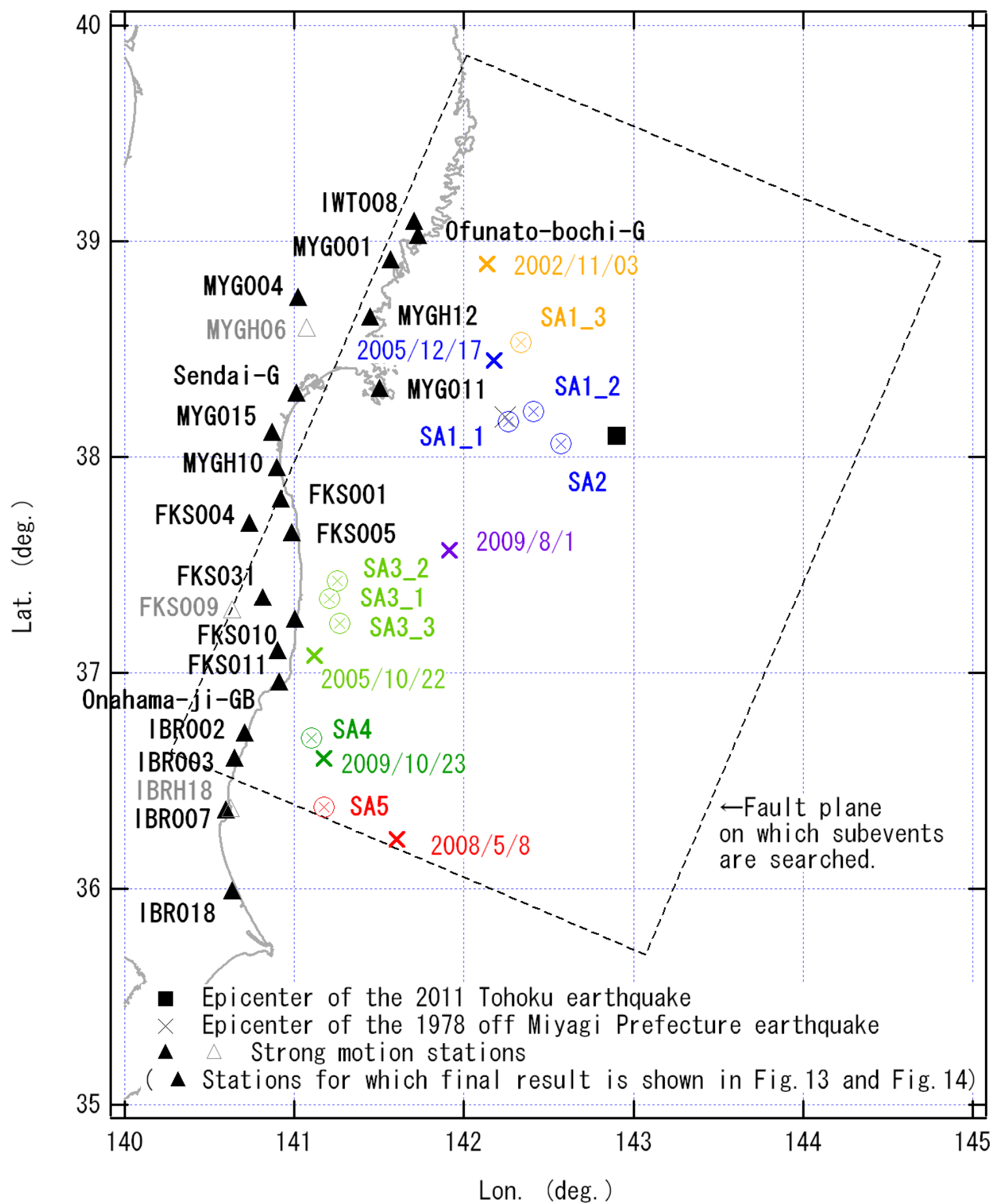

Fig. 1 Proposed source model composed of nine super asperities. The triangles indicate strong motion stations. The crosses indicate the epicenters of the small events used to determine the phase characteristics of the Green's functions. 
Table 1 Small events used to determine the phase characteristics of the Green's functions

\begin{tabular}{|l|l|l|l|l|l|l|l|l|l|}
\hline & SA1_1 & SA1_2 & SA1_3 & SA2 & SA3_1 & SA3_2 & SA3_3 & SA4 & SA5 \\
\hline IWT008 & 20051217 & & 20021103 & 20051217 & & & & & \\
Ofunato-bochi-G & 20050816 & & 20021103 & 20110309 & & & & \\
MYG001 & 20051217 & & 20051217 & 20051217 & & & & \\
MYG004 & 20051217 & & 20021103 & 20051217 & & & & & \\
\hline MYGH12 & 20051217 & Same as & 20021103 & 20051217 & Same as & Same as & Same as & Same as & Same as \\
\hline MYG011 & 20051217 & left & 20051217 & 20051217 & left & left & left & left & left \\
\hline Sendai-G & 20110310 & & 20021103 & 20021103 & & & & & \\
MYG015 & 20051217 & & 20021103 & 20090801 & & & & & \\
\hline MYGH10 & 20050816 & & 20021103 & 20110309 & & & & & \\
\hline FKS001 & 20050816 & & 20021103 & 20090801 & & & & & \\
\hline FKS004 & 20051217 & & & 20051217 & 20051022 & & & 20091023 & 20080508 \\
\hline FKS005 & 20050816 & & & 20090801 & 20051022 & & & 20091023 & 20080508 \\
\hline FKS031 & 20051217 & & & 20051217 & 20051022 & & & 20091023 & 20080508 \\
\hline FKS010 & 20050816 & & & 20090801 & 20051022 & & & 20091023 & 20080508 \\
\hline FKS011 & 20051217 & Same as & Same as & 20090801 & 20051022 & Same as & Same as & 20091023 & 20080508 \\
\hline Onahama-ji-GB & 20050816 & left & left & 20100613 & 20051022 & left & left & 20110311 & 20080508 \\
\hline IBR002 & 20050816 & & & 20090801 & 20051022 & & & 20091023 & 20080508 \\
\hline IBR003 & 20050816 & & & 20090801 & 20051022 & & & 20091023 & 20080508 \\
IBR007 & 20050816 & & & 20090801 & 20051022 & & & 20091023 & 20080508 \\
\hline IBR018 & 20050816 & & & 20050816 & 20051022 & & & 20091023 & 20080508 \\
\hline
\end{tabular}

Table 2 Nonlinear parameters used to correct the Green's functions

\begin{tabular}{|l|l|r|r|}
\hline & & $\nu 1$ & $\nu 2$ \\
\hline MYG004 & Tsukidate & 0.90 & 0.005 \\
\hline MYG015 & Iwanuma & 0.67 & 0.010 \\
MYGH10 & Yamamoto & 0.80 & 0.008 \\
\hline FKS001 & Soma & 0.90 & 0.005 \\
\hline FKS005 & Haramachi & 0.90 & 0.005 \\
\hline
\end{tabular}

\section{OFF MIYAGI PREFECTURE}

The iterative forward modeling was begun off Miyagi Prefecture. Fig. 2 shows the observed ground velocities at three strong-motion stations MYG011, MYGH12 and MYGH06 located in Miyagi Prefecture. As already pointed out by many researchers ${ }^{18)}$, strong ground motions in Miyagi Prefecture include two distinctive wave packets, indicating contributions from at least two subevents. As other researchers $\mathrm{did}^{19)}$, the locations and the rupture times of the subevents were then determined based on the arrival times of the S-waves corresponding to different wave packets. In this process, selection of the S-wave phase at different stations might have a considerable effect on the result; if we wrongly assign S-wave phases from different subevents to the same subevent, it will obviously lead to incorrect estimates. The greater the distance between the stations used for the analysis, the greater the possibility of a mistake of this type. Therefore, in this study, closely located stations were used. In particular, for Miyagi Prefecture, the stations shown in Fig. 2 were selected and the arrival times of the S-waves corresponding to different wave packets were determined, as indicated by the vertical red bars in Fig. 2. These stations were selected because the arrival of the S-waves was quite distinct. A fault plane with a strike angle of $203^{\circ}$ and a dip angle of $10^{\circ}$ was then assumed (large rectangle in Fig. 1), which includes the hypocenter determined by the JMA (the strike and dip angles were determined by referring to the CMT solution by the JMA). For each point on the fault and each waveform in Fig. 2, the rupture time, which is consistent with the arrival time of the S-wave, was determined. The rupture times determined from different waveforms should coincide if the point on the fault corresponds to the true location of the rupture. Thus, the point on the fault with the minimum standard deviation with respect to the estimated rupture times was adopted as the location of the subevent.

The estimated locations on the fault plane are indicated as "SA1_1" and "SA2" in Fig. 1 (SA stands for Super Asperity). The estimated location of SA1_1 was close to the hypocenter of the 1978 
off Miyagi Prefecture earthquake $\left(\mathrm{M}_{\mathrm{w}} 7.6\right)$. The results can be compared with other studies as follows: SA1 1 was involved in the SMGA1 of Asano and Iwata ${ }^{19)}$, Asperity-1 of Satoh ${ }^{20)}$ and Asp1 of Kawabe et al. ${ }^{\overline{2} 1}$. SA2 was involved in the SMGA2 of Asano and Iwata ${ }^{19)}$, Asperity-2 of Satoh ${ }^{20)}$ but it was to the south of Asp2 of Kawabe et al. ${ }^{21)}$. In the model of Kurahashi and Irikura ${ }^{18)}$, the eastern subevent ruptured first, while in our model, the western subevent ruptured first.

Assuming rectangular super asperities which involve the estimated locations as local rupture starting points, the parameters for the super asperities were then determined through an iterative forward modeling approach. The estimated parameters included the length, width, seismic moment of the super asperities as well as the relative locations of the super asperities with respect to the rupture starting points. In the iterative forward modeling approach, the parameters were determined so that the velocity waveforms in the strong motion stations over the frequency range from $0.2-1 \mathrm{~Hz}$ were reproduced as accurately as possible. Throughout the study, the rupture velocity was fixed to $3.0 \mathrm{~km} / \mathrm{s}$ and the rise time was fixed to the width of the super asperity divided by the rupture velocity and multiplied by 0.25 .
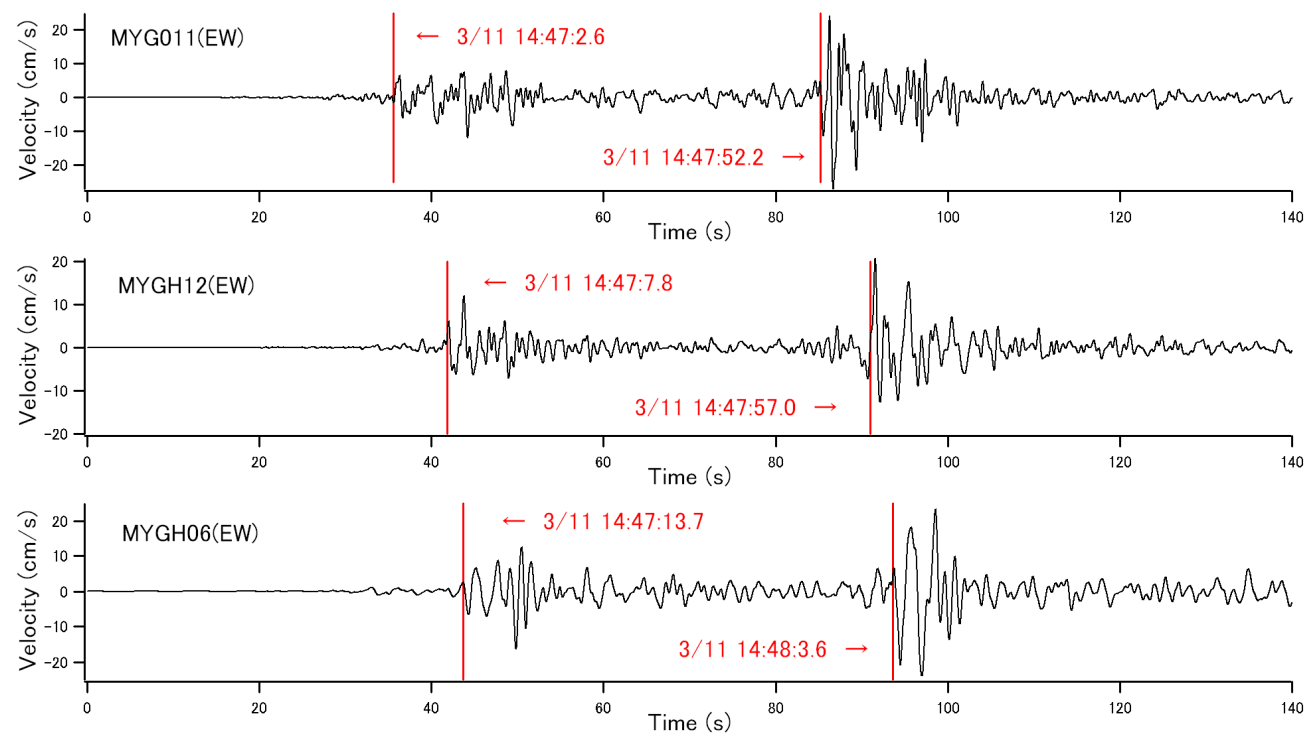

Fig. 2 Observed ground velocities at MYG011, MYGH12 and MYGH06

(EW components; for MYGH12 and MYGH06, borehole records are shown)

Table 3 Parameters for the super asperity model

\begin{tabular}{|l|l|l|l|l|l|l|l|}
\hline & $\begin{array}{l}\text { Rupture } \\
\text { time }(\mathrm{h}: \mathrm{m}: \mathrm{s})\end{array}$ & $\begin{array}{l}\text { Length } \\
(\mathrm{km})\end{array}$ & $\begin{array}{l}\text { Width } \\
(\mathrm{km})\end{array}$ & $\begin{array}{l}\text { Area } \\
\left(\mathrm{km}^{2}\right)\end{array}$ & $\mathrm{M}_{0}(\mathrm{Nm})$ & Slip (m) & $\begin{array}{l}\text { Rise time } \\
(\mathrm{s})\end{array}$ \\
\hline SA1_1 & $14: 46: 43.5$ & 3.0 & 2.0 & 6.0 & $8.00 \mathrm{E}+18$ & 28.3 & 0.17 \\
\hline SA1_2 & $14: 46: 46.9$ & 4.0 & 3.0 & 12.0 & $8.00 \mathrm{E}+18$ & 14.1 & 0.25 \\
\hline SA1_3 & $14: 47: 33.4$ & 4.0 & 2.0 & 8.0 & $4.00 \mathrm{E}+18$ & 10.6 & 0.17 \\
\hline SA2 & $14: 47: 26.3$ & 3.5 & 3.0 & 10.5 & $2.10 \mathrm{E}+19$ & 42.4 & 0.25 \\
\hline SA3_1 & $14: 47: 57.1$ & 3.0 & 4.0 & 12.0 & $3.00 \mathrm{E}+18$ & 5.3 & 0.33 \\
\hline SA3_2 & $14: 48: 04.4$ & 3.0 & 4.0 & 12.0 & $3.00 \mathrm{E}+18$ & 5.3 & 0.33 \\
\hline SA3_3 & $14: 48: 15.0$ & 6.0 & 2.0 & 12.0 & $5.00 \mathrm{E}+18$ & 8.8 & 0.17 \\
\hline SA4 & $14: 48: 25.8$ & 8.0 & 3.0 & 24.0 & $9.00 \mathrm{E}+18$ & 8.0 & 0.25 \\
\hline SA5 & $14: 48: 30.9$ & 7.0 & 7.0 & 49.0 & $2.00 \mathrm{E}+19$ & 8.7 & 0.58 \\
\hline
\end{tabular}




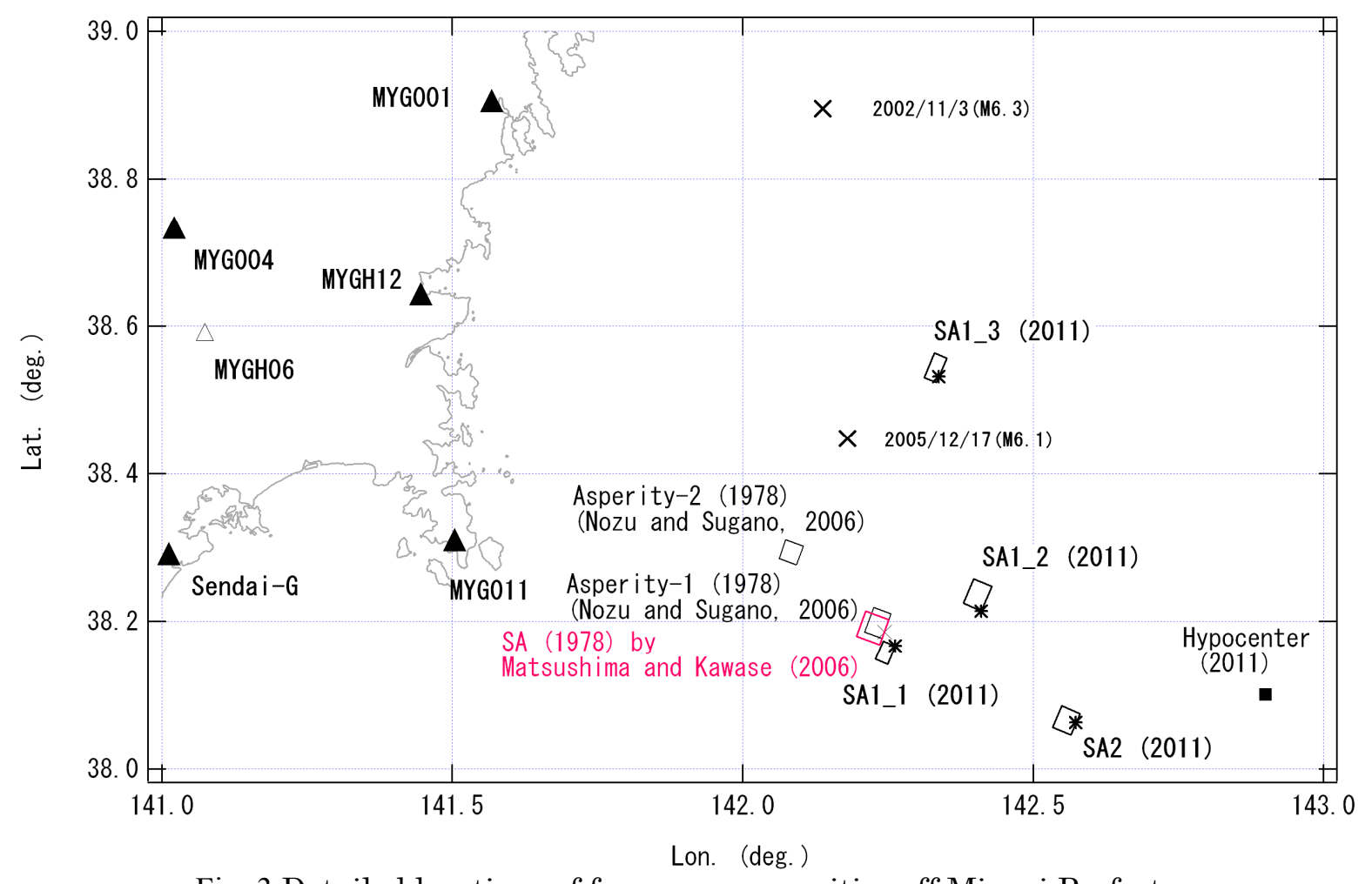

Fig. 3 Detailed locations of four super asperities off Miyagi Prefecture

The estimated parameters for SA1_1 and SA2 are listed in Table 3. The detailed locations of SA1_1 and SA2 are shown in Fig.3. The implications of these parameters will be discussed later. It should be noted that different assumptions on the rupture velocity may lead to different estimates of the size of the super asperities, although the value of the rupture velocity adopted here $(3.0 \mathrm{~km} / \mathrm{s})$ is a typical value in practical applications ${ }^{12) 13}$. This point will also be discussed in a later section. On the other hand, the size of the small event had little effect on the estimated parameters of the super asperities, although details on this topic are not included in this paper because of space limitations.

The resultant waveforms, i.e., the synthetic waveforms with contributions from two super asperities SA1_1 and SA2, are compared with the observed waveforms in Fig. 4. There was good agreement between the observed and synthetic waveforms. In particular, the amplitude and width of the S-wave pulses, which arrived with an interval of about $50 \mathrm{~s}$, were well reproduced, indicating that the estimated seismic moment and the size of the super asperities were appropriate.

In Fig. 4, however, some phases included in the observed waveforms were not included in the synthetic waveforms. For example, the phases following the S-wave pulse from SA1_1 (at around $34 \mathrm{~s}$ at Sendai-G and around $52 \mathrm{~s}$ at MYG001 as indicated by crosses) were not included in the synthetic waveforms. Besides, the amplitude of the first wave packet at northern stations including Ofunato-bochi-G was underestimated if we considered only SA1_1 and SA2. Therefore, another super asperity SA1_2, which ruptured just after SA1_1, was introduced. The location of SA1_2 was determined by taking into account the arrival times at Sendai-G, etc, as shown in Fig. 1. The location of SA1_2 was involved in the SMGA1 of Asano and Iwata ${ }^{19)}$ and Asp1 of Kawabe et al. ${ }^{21}$. The parameters for SA1_2 were determined in the same way as the parameters for SA1_1 and SA2. The estimated parameters for SA1_2 are listed in Table 3. The detailed location of SA1_ 2 is shown in Fig. 3. The synthetic waveform at MYG001 with contributions from three super asperities SA1_1, SA1_2 and SA2 is compared with the observed waveform in Fig. 5 (top). The phase around $52 \mathrm{~s}$, which could not be reproduced with two super asperities, was successfully reproduced in this case as indicated by a circle.

In Fig.5 (top), however, the phase around $90 \mathrm{~s}$, which is indicated by a cross, cannot be explained if we consider only three super asperities. A similar tendency can be found at other stations near the 

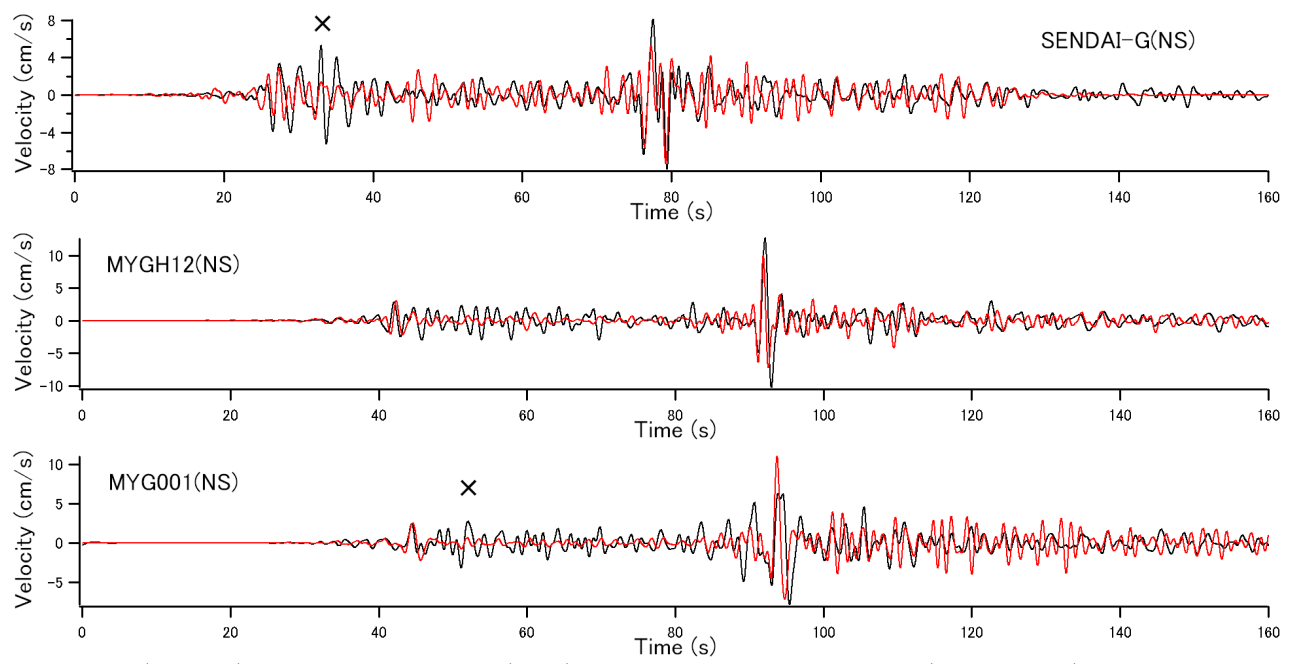

Fig. 4 Observed (black) and synthetic (red) velocity waveforms $(0.2-1 \mathrm{~Hz})$. Contributions from SA1_1 and SA2 are considered in the synthetic waveforms.

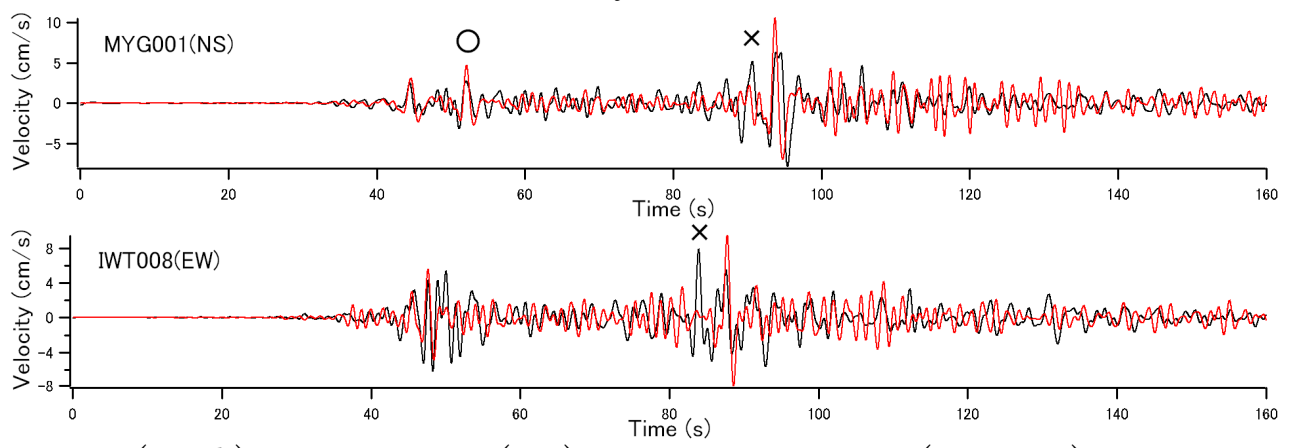

Fig. 5 Observed (black) and synthetic (red) velocity waveforms $(0.2-1 \mathrm{~Hz})$. Contributions from SA1_1, SA1_2 and SA2 are considered in the synthetic waveforms.
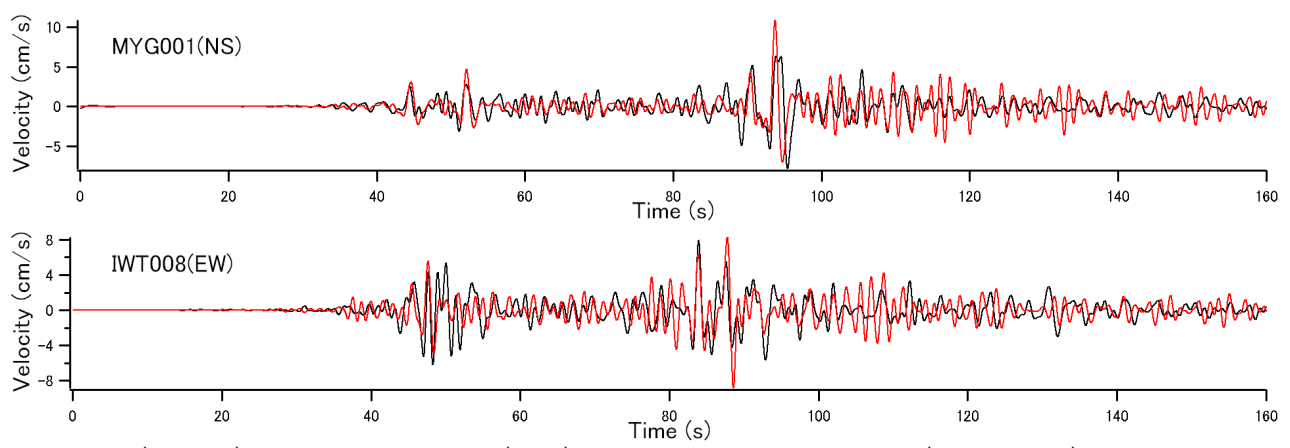

Fig. 6 Observed (black) and synthetic (red) velocity waveforms $(0.2-1 \mathrm{~Hz})$. Contributions from four super asperities off Miyagi Prefecture are considered in the synthetic waveforms.

border of Miyagi and Iwate Prefectures, especially for EW components. For example, the synthetic waveform at IWT008, with contributions from three super asperities SA1_1, SA1_2 and SA2, is compared with the observed waveform in Fig. 5 (bottom). The phase around $84 \mathrm{~s}$, which is indicated by a cross, is not included in the synthetic waveform. If we consider its arrival time, it is not reasonable to assume that the phase came from SA2. Therefore, another super asperity SA1_3, which ruptured just before SA2, was introduced. The location of SA1_3 was determined by taking into account the arrival times at IWT008, etc. It was located to the north of other super asperities as shown in Fig. 1. This location did not correspond to asperities or SMGAs by other researchers, although it was close to the northern end of Asp1 of Kawabe et al. ${ }^{21}$. The parameters for SA1_3 were determined in the same way as the parameters for other super asperities. The estimated parameters for SA1_3 are 
listed in Table 3. The detailed location of SA1_3 is shown in Fig. 3. The synthetic waveforms at MYG001 and IWT008 with contributions from four super asperities are compared with the observed waveforms in Fig.6. The synthetic waveforms with contributions from four super asperities agreed well with the observed waveforms at these stations. The results for other stations will be discussed later.

\section{OFF FUKUSHIMA PREFECTURE}

So far, the super asperities off Miyagi Prefecture have been investigated. At stations around the border of Miyagi and Fukushima Prefectures, such as MYGH10 and FKS001, the contributions from four super asperities off Miyagi Prefecture could almost explain the observed waveforms as shown in Fig. 7. At stations further south, however, the contributions from the super asperities off Miyagi Prefecture alone could not explain the observed waveforms as shown in Fig. 8. In particular, three distinctive pulses were present in the observed waveforms as indicated by crosses, which did not appear in the synthetics. To explain these pulses, three super asperities, namely, SA3_1, SA3_2 and SA3_3, were introduced. The locations and the rupture times for them were estimated based on the arrival times of the S-waves. The estimated locations of the super asperities were close to the coast of Fukushima Prefecture as shown in Fig. 1. The central one ruptured first, followed by the northern one, and finally the southern one. Among other source models, SMGA3 of Asano and Iwata ${ }^{19)}$, Asp4 of Kawabe et al. ${ }^{21)}$ and SMGA4 of Kurahashi and Irikura ${ }^{18)}$ involved the locations of the super asperities or were at least close to them. The parameters for the super asperities were determined through iterative forward modeling. The resultant parameters are given in Table 3. The detailed locations of the super asperities are shown in Fig. 9 (left). The synthetic waveforms, with contributions from three super asperities off Fukushima Prefecture, are compared with the observed waveforms in Fig. 10. The agreement between the observed and synthetic waveforms was satisfactory.
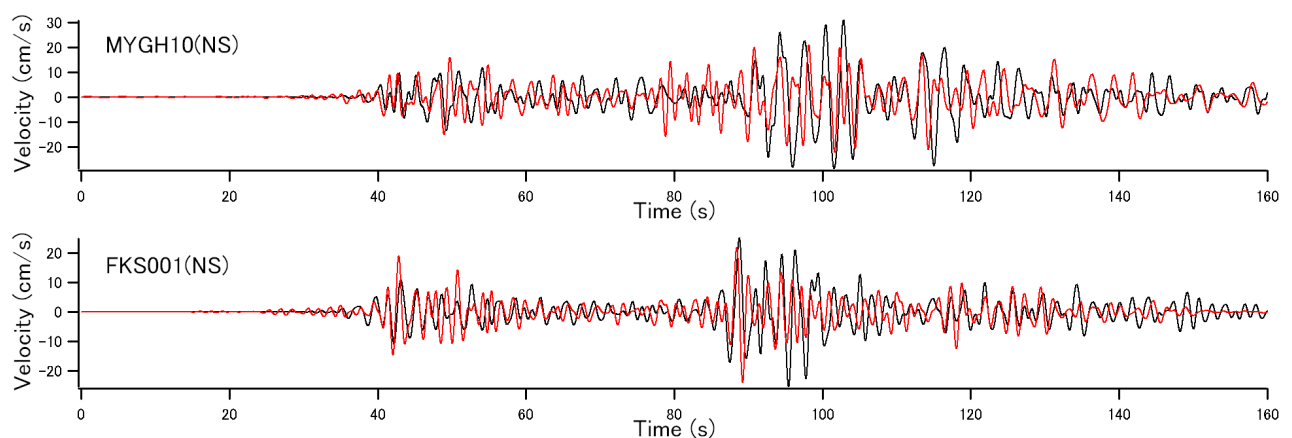

Fig. 7 Observed (black) and synthetic (red) velocity waveforms $(0.2-1 \mathrm{~Hz})$. Contributions from four super asperities off Miyagi Prefecture are considered in the synthetic waveforms.
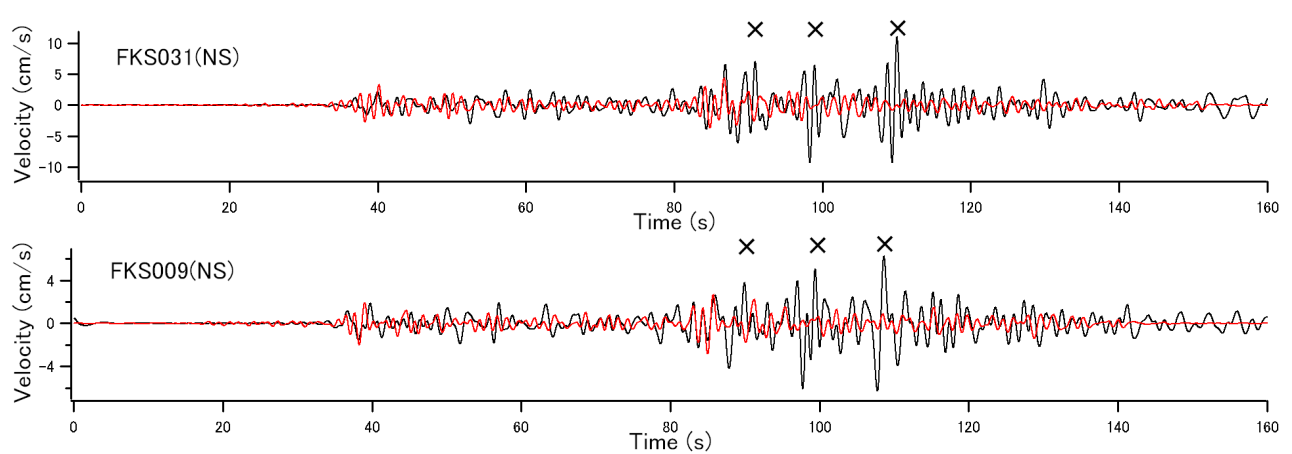

Fig. 8 Observed (black) and synthetic (red) velocity waveforms $(0.2-1 \mathrm{~Hz})$. Contributions from four super asperities off Miyagi Prefecture are considered in the synthetic waveforms. 

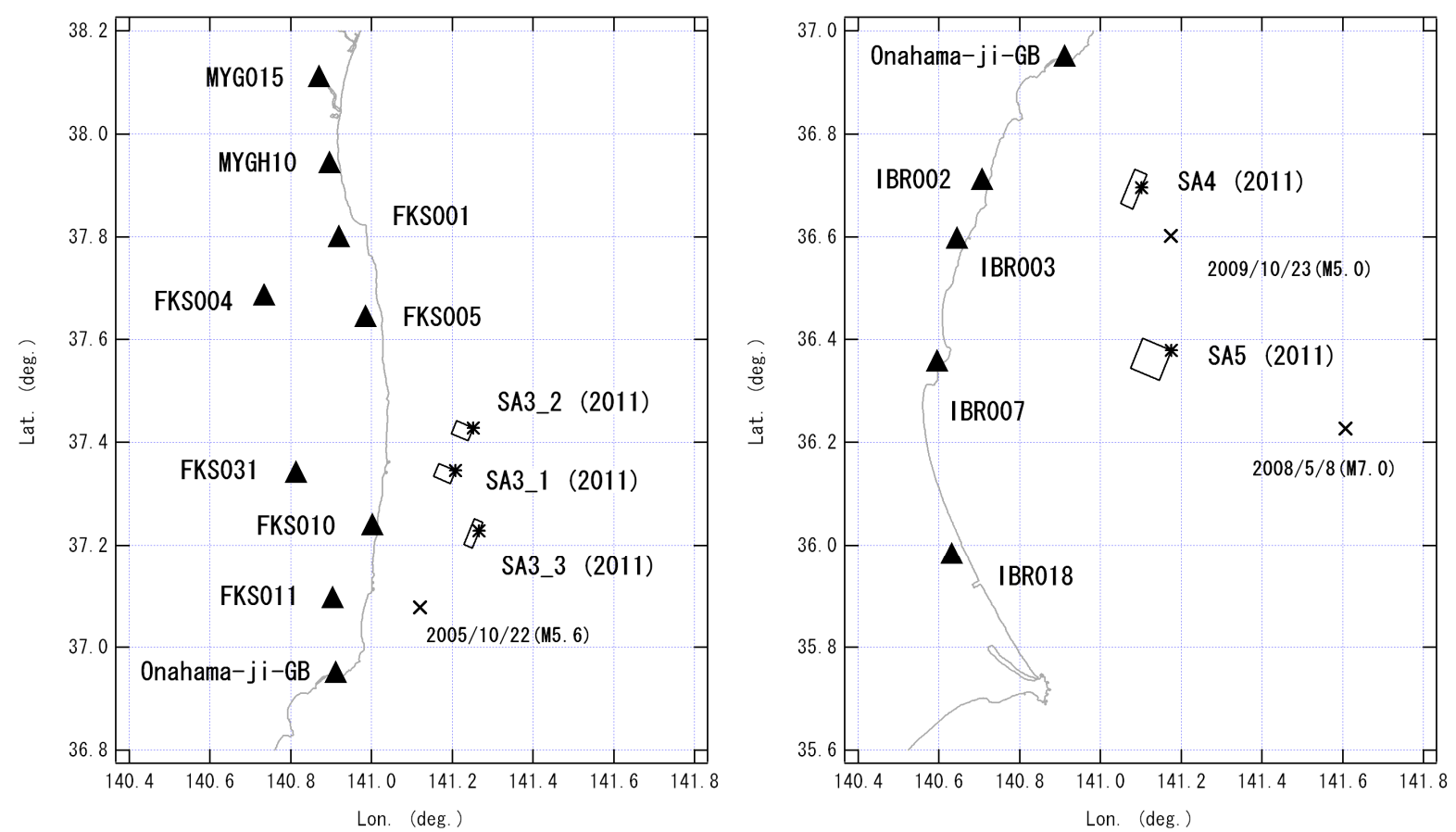

Fig. 9 Detailed locations of super asperities off Fukushima (left) and Ibaraki (right)

Prefectures
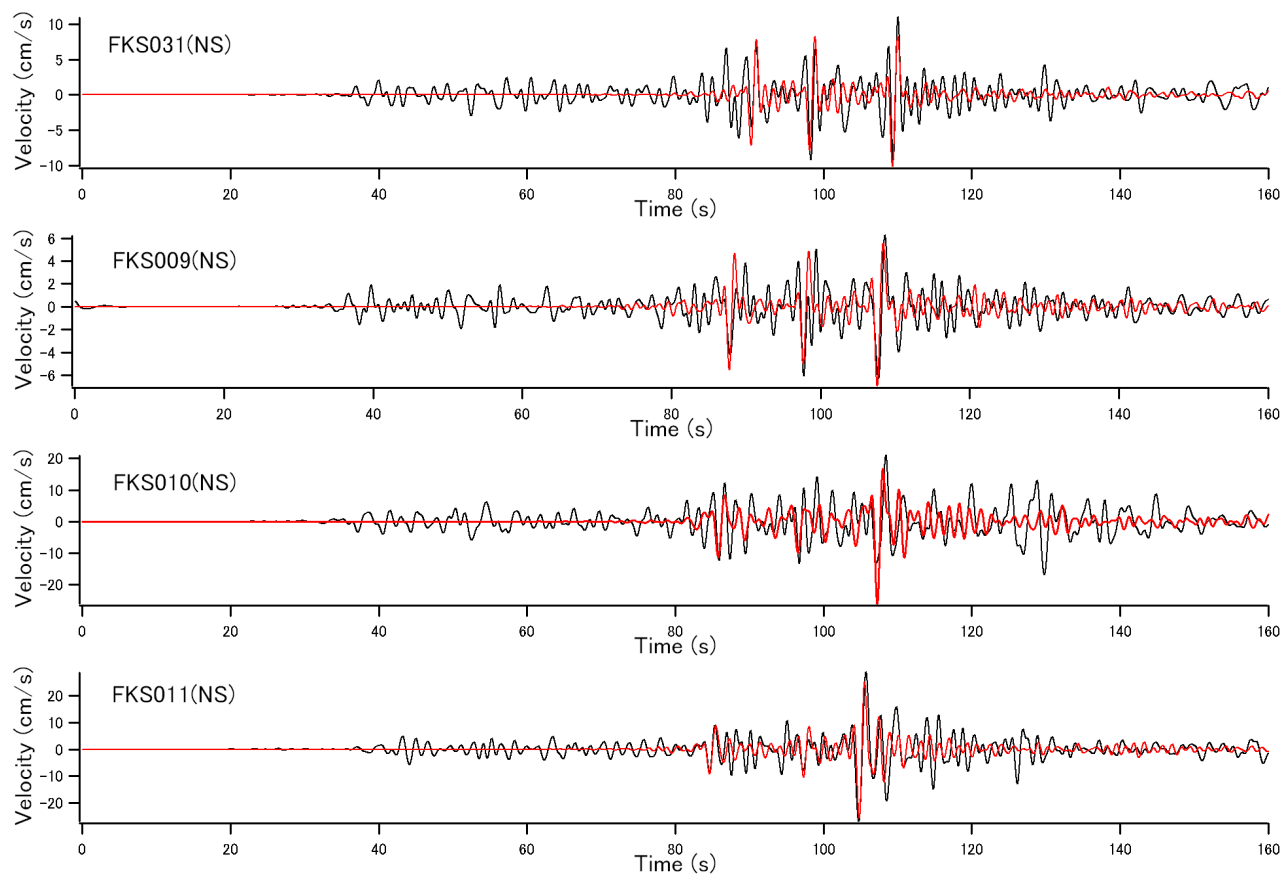

Fig. 10 Observed (black) and synthetic (red) velocity waveforms $(0.2-1 \mathrm{~Hz})$. Contributions from three super asperities off Fukushima Prefecture are considered in the synthetic waveforms.

\section{OFF IBARAKI PREFECTURE}

In Fig. 11, the synthetic waveforms, with contributions from seven super asperities off Miyagi Prefecture through Fukushima Prefecture, are compared with the observed waveforms at two strong motion stations, IBR002 and IBR003, located in northern Ibaraki Prefecture. The synthetic waveforms 
could explain only the initial part of the observed waveforms. Therefore, another super asperity SA4 was introduced to explain strong ground motions in the region. The location and rupture time of SA4 were estimated based on the arrival times of the S-waves. The estimated location of SA4 was close to the coast of Ibaraki Prefecture as shown in Fig. 1. Among other source models, SMGA4 of Asano and Iwata ${ }^{19)}$ and Asp5 of Kawabe et al. ${ }^{21)}$ were relatively close to SA4.

The existence of SA4 at this location was supported by other evidence. As shown in Nozu and Wakai ${ }^{16}$, if we substitute the Fourier phase of the main shock record at IBR007 with that of the record of the October 23, 2009, east off Ibaraki Prefecture earthquake $\left(\mathrm{M}_{\mathrm{J}} 5.0\right)$, a waveform similar to the main shock record can obtained. Obviously such similarity in the Fourier phase between the large and small events cannot be expected when the effect of multiple shocks is evident in the records of the large event. That is, such similarity indicates that the effect of one particular subevent was predominant in the records of the large event; such a subevent should be located close to the site IBR007. Additionally, the October 23, 2009, event occurred close to SA4. Consequently, the path and site effects were shared between the event and SA4, which led to the similarity of the Fourier phase.

The parameters for SA4 were determined through iterative forward modeling. The resultant parameters are given in Table 3. The detailed location of SA4 is shown in Fig. 9 (right). The synthetic waveforms, with contributions from seven super asperities off Miyagi Prefecture through Fukushima Prefecture, plus SA4, are compared with the observed waveforms in Fig. 12. The agreement between the observed and synthetic waveforms was satisfactory at IBR002, IBR003 and IBR007.

At IBR018, located in southern Ibaraki Prefecture, however, the synthetic waveforms from eight super asperities significantly underestimated those observed (as shown by a cross in Fig. 12). Therefore, another super asperity SA5 was introduced to explain strong ground motions in the region. The location and rupture time of SA5 were estimated based on the arrival times of the S-waves. The estimated location of SA5 was off the coast of Ibaraki Prefecture as shown in Fig. 1. Among other source models, the SMGA5 of Kurahashi and Irikura ${ }^{18)}$ was relatively close to SA5.

The existence of SA5 at this location was supported by other evidence. As shown in Nozu and Wakai ${ }^{16)}$, if we substituted the Fourier phase of the main shock record at IBR018 with that of the record of the May 8, 2008, far east off Ibaraki Prefecture earthquake $\left(\mathrm{M}_{\mathrm{J}} 7.0\right)$, a waveform similar to the main shock record could be obtained. The May 8, 2008 event occurred close to SA5. Consequently, the path and site effects were shared between the event and SA5, which led to the similarity of the Fourier phase.

The parameters for SA5 were determined through iterative forward modeling. The resultant parameters are given in Table 3. The detailed location of SA5 is shown in Fig. 9 (right). SA5 is relatively large if it is compared with other super asperities of the same event, because the time width of the S-wave pulse at IBR018 was larger than those at other stations. The synthetic waveform with contributions from nine super asperities off Miyagi Prefecture through Ibaraki Prefecture at IBR018 will be compared with the observed waveform later. The agreement between the observed and synthetic waveforms was improved by introducing SA5.

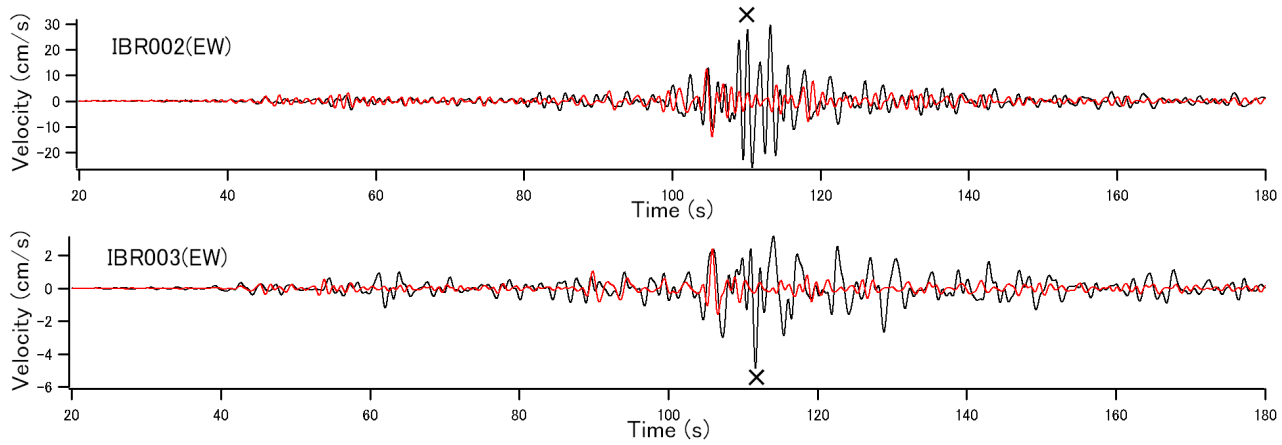

Fig. 11 Observed (black) and synthetic (red) velocity waveforms $(0.2-1 \mathrm{~Hz})$. Contributions from seven super asperities off Miyagi through Fukushima are considered in the synthetic waveforms. 

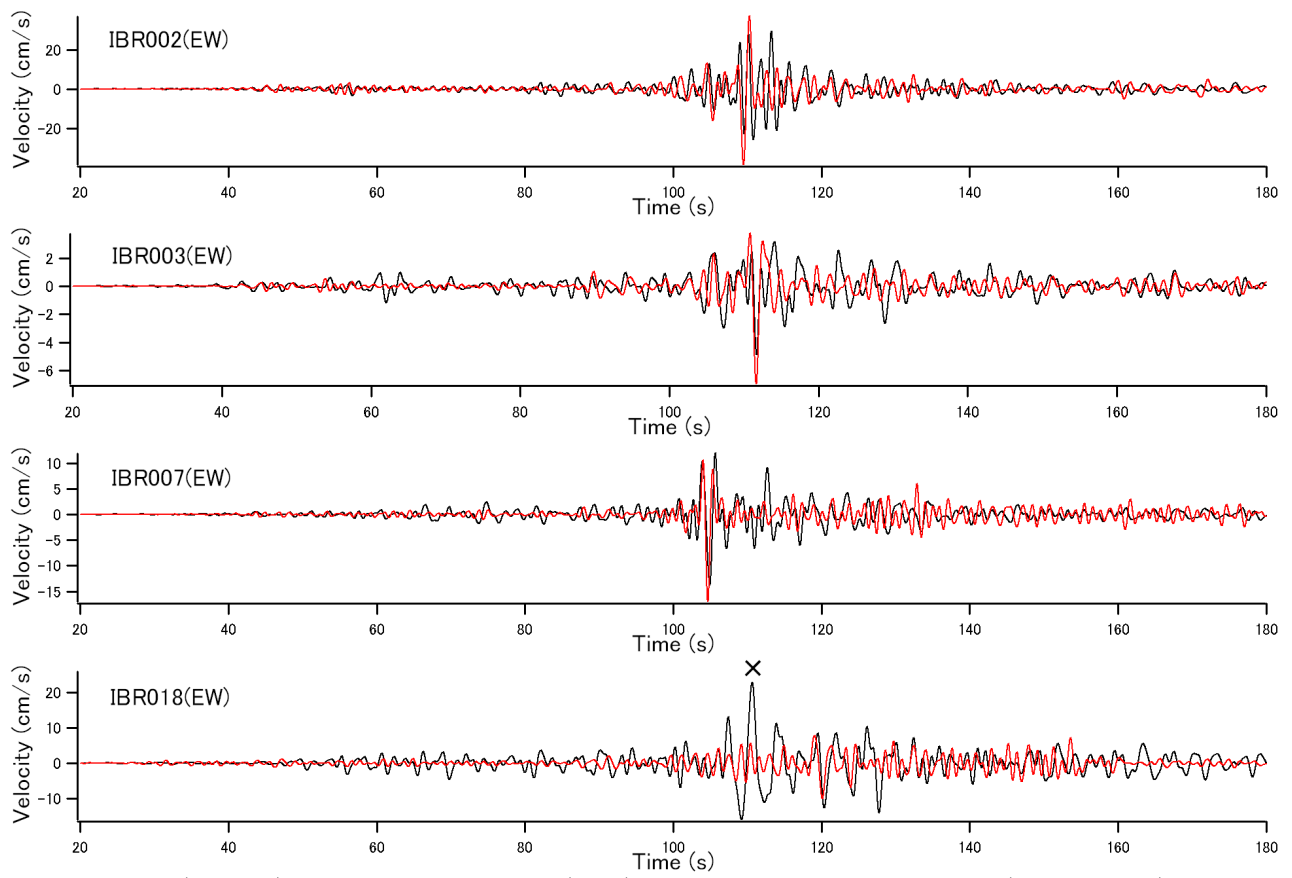

Fig. 12 Observed (black) and synthetic (red) velocity waveforms $(0.2-1 \mathrm{~Hz})$. In addition to contributions from seven super asperities off Miyagi through Fukushima, contributions from SA4 off Ibaraki are considered in the synthetic waveforms.

\section{SIMULATION BASED ON THE WHOLE MODEL, AND DISCUSSION}

The synthetic velocity waveforms $(0.2-1 \mathrm{~Hz})$ with contributions from the nine super asperities off Miyagi Prefecture through Ibaraki Prefecture at 20 stations (Fig. 1) are compared with those observed in Fig. 13. The synthetic Fourier spectra $(0.2-10 \mathrm{~Hz}$, root of the squared sum of two horizontal components, smoothed with a Parzen window with a band width of $0.05 \mathrm{~Hz}$ ) with contributions from the nine super asperities off Miyagi Prefecture through Ibaraki Prefecture at 20 stations (Fig. 1) are compared with those observed in Fig. 14. The agreement between the observed and synthetic waveforms was quite satisfactory both for the velocity waveforms $(0.2-1 \mathrm{~Hz})$ and the Fourier spectra $(0.2-10 \mathrm{~Hz})$. The strong motion stations used to construct the source model are summarized in Table 4.

One of the most important aspects of the source model developed here is that it is based on the recognition that the rupture of an asperity (or a super asperity) produces a coherent pulse in the near source region. Such recognition was the basis for the development of the source model of Kamae and Irikura $^{22)}$ for the 1995 Hyogo-ken Nanbu earthquake, which was a shallow crustal earthquake. This study showed that the same recognition can also be the basis for the development of a source model for a huge subduction earthquake, as was shown for the 2003 Tokachi-oki earthquake $\left(\mathrm{M}_{\mathrm{J}} 8.0\right)$ in the author's previous studies ${ }^{4) 6}$. In terms of the 2011 Tohoku earthquake, the super asperities several kilometers long were required to accurately represent the S-wave pulses in the near source region, as shown in this study. Although other authors ${ }^{18) 19(20) 21)}$ proposed "asperities" or "SMGAs" several tens of kilometers long for the same earthquake, it is difficult to reproduce the short-period S-wave pulses based on these source models, because, in these models, the rupture duration of a subevent is more than $10 \mathrm{~s}$ as long as a rupture velocity of around $3.0 \mathrm{~km} / \mathrm{s}$ is used. The value of the rupture velocity adopted here $(3.0 \mathrm{~km} / \mathrm{s})$ is a typical value in practical applications ${ }^{1213)}$. Strictly speaking, what this study revealed was the rupture duration of the super asperities, rather than the size of them; different assumptions on the rupture velocity may lead to different estimates of the size of the subevents. Even if we assume a super asperity 1.5 times longer and, at the same time, a rupture velocity 1.5 times greater $(4.5 \mathrm{~km} / \mathrm{s})$ (in this case we are assuming a super shear rupture $\left.{ }^{23}\right)$, the synthetic velocity waveforms in the frequency range from 0.2 to $1 \mathrm{~Hz}$ do not differ significantly. This type of uncertainty, 

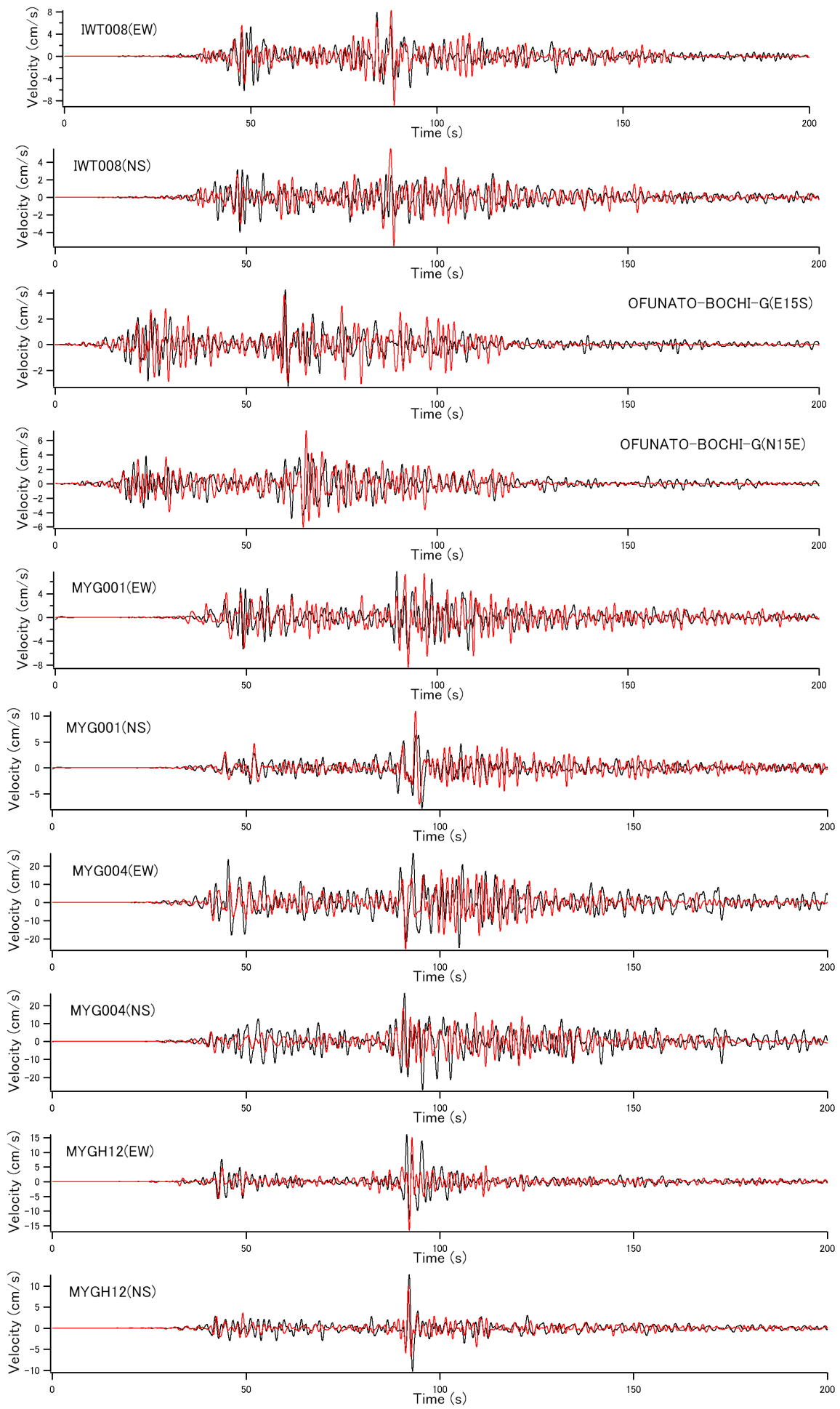

Fig. 13 Observed (black) and synthetic (red) velocity waveforms $(0.2-1 \mathrm{~Hz})$. Contributions from nine super asperities off Miyagi through Ibaraki are considered in the synthetic waveforms. 

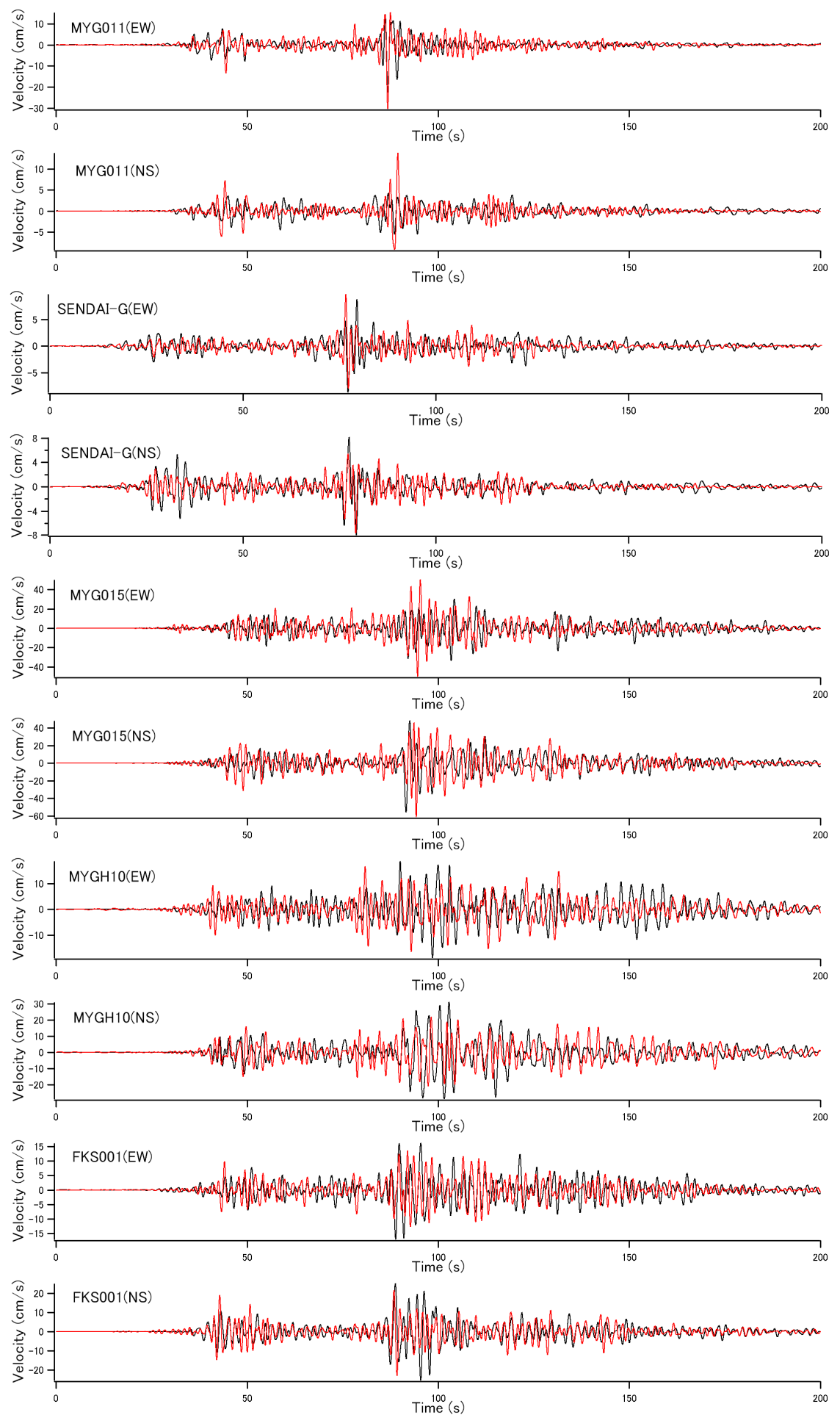

Fig. 13 (Continued) 

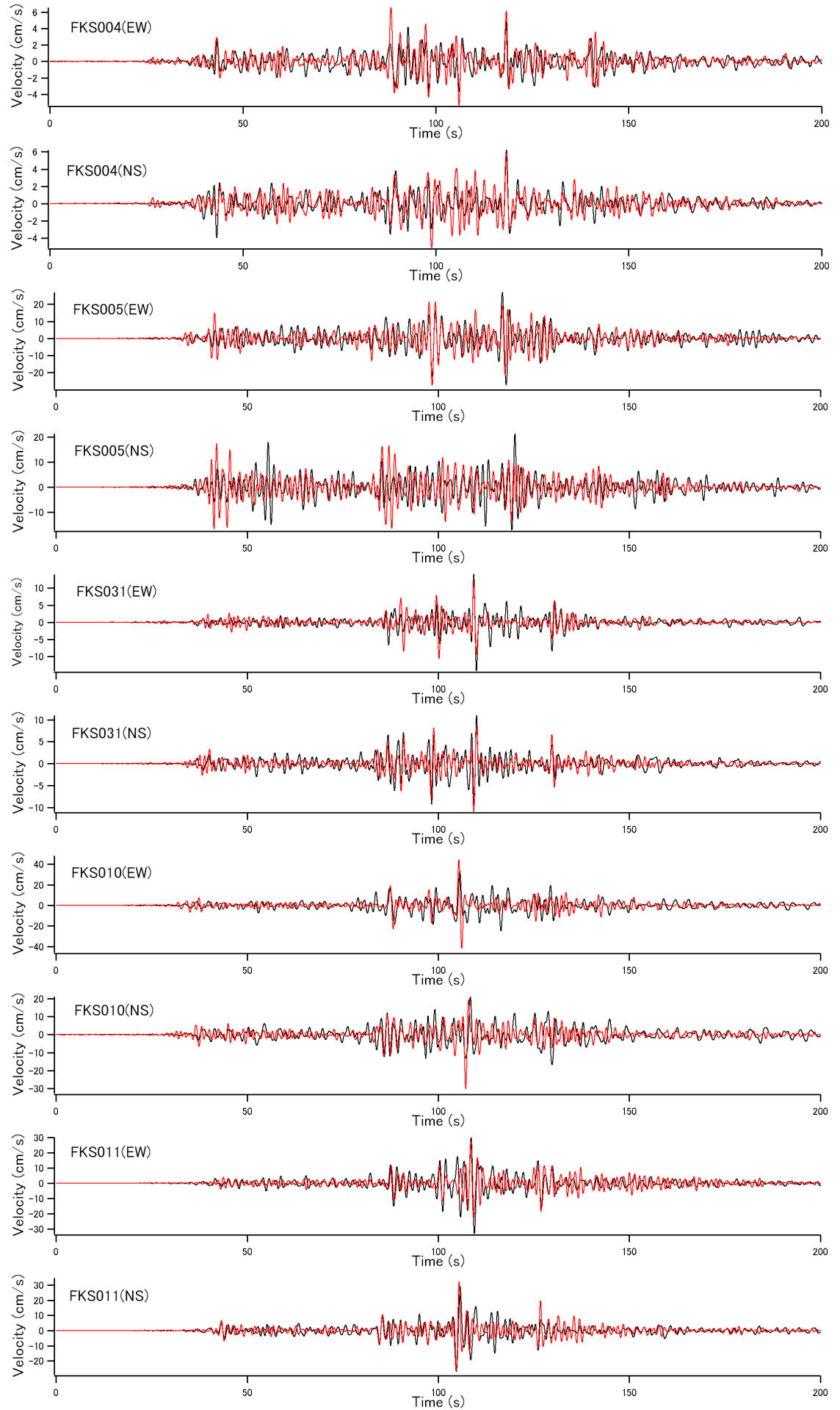

Fig. 13 (Continued) 

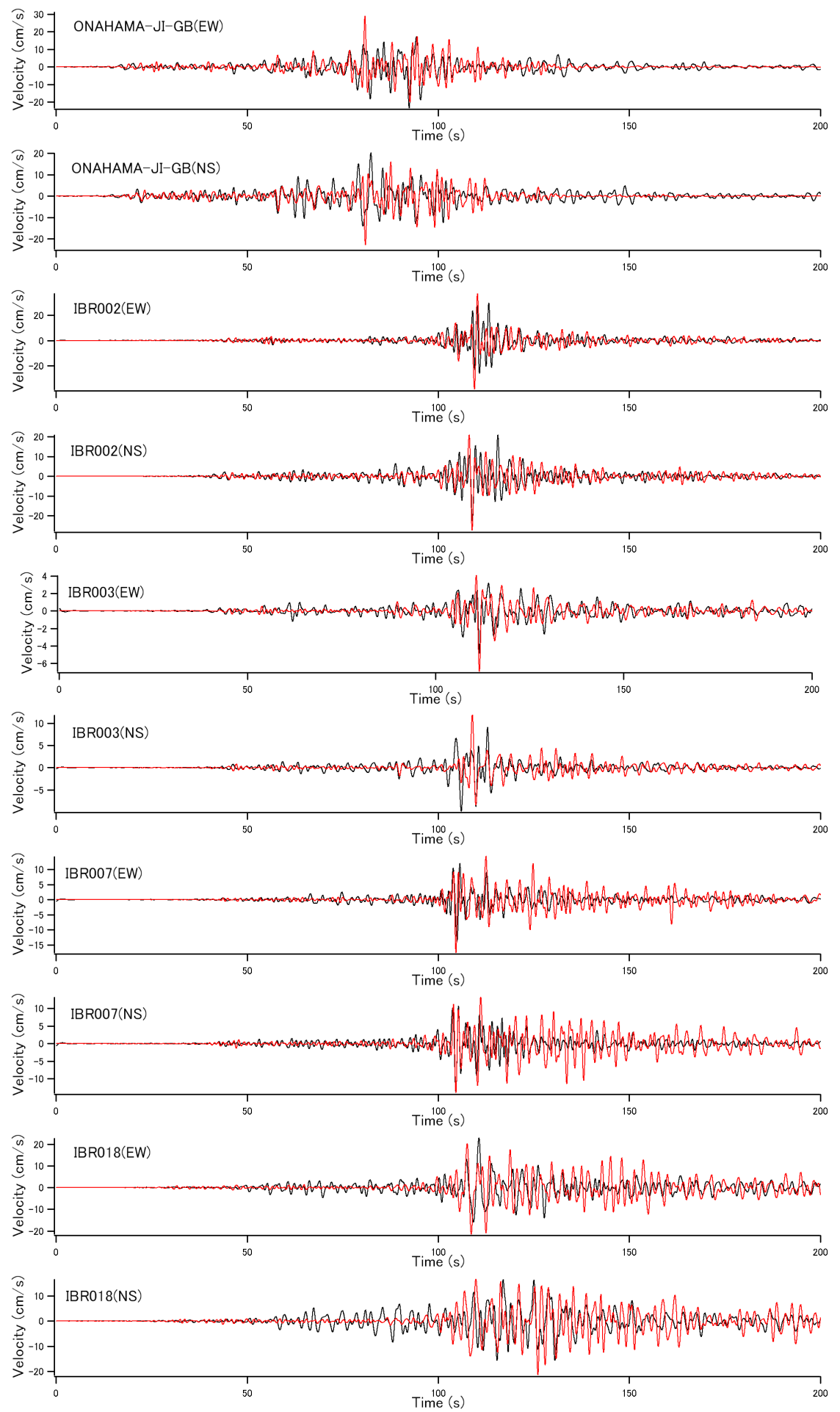

Fig. 13 (Continued) 

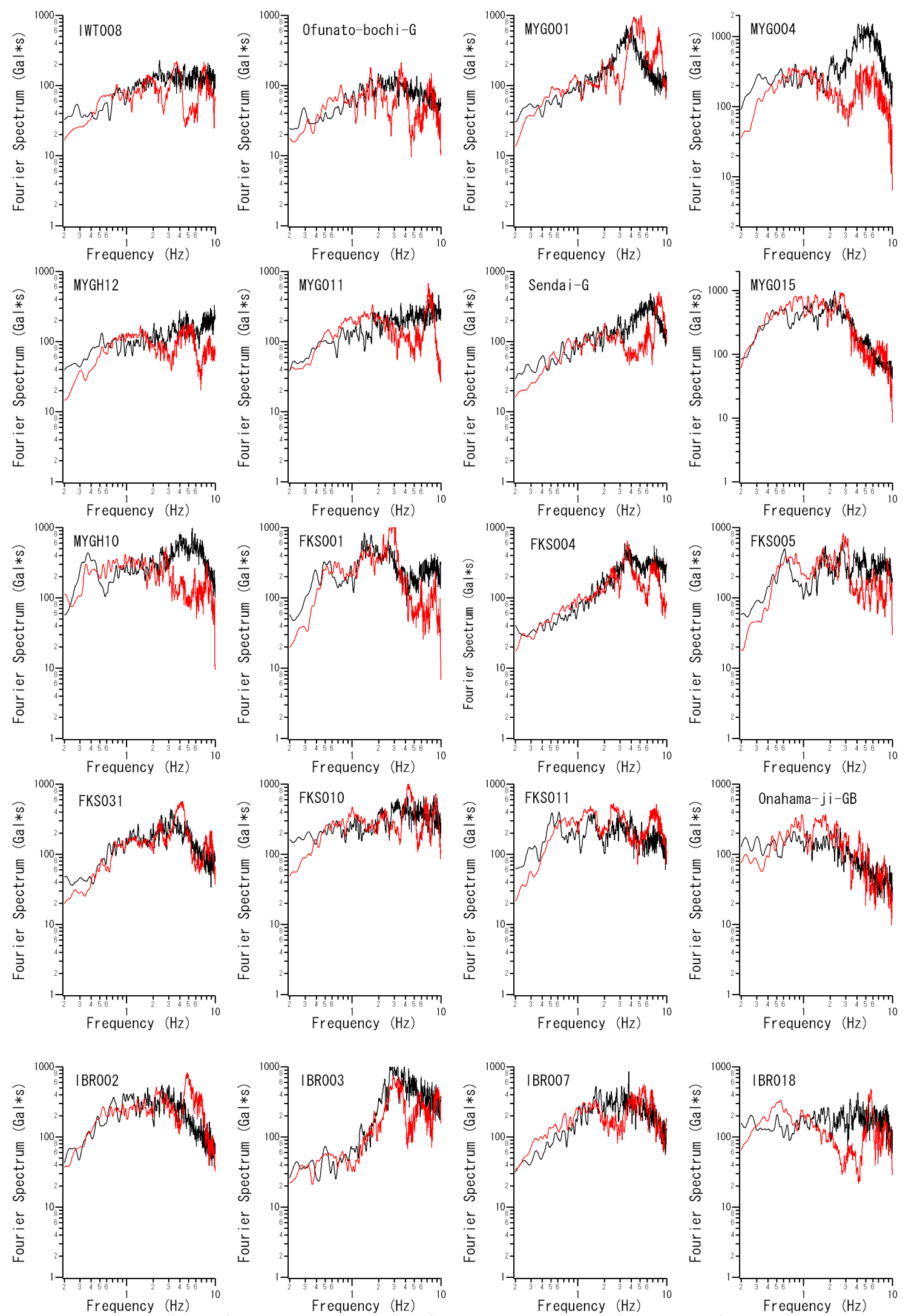

Fig. 14 Observed (black) and synthetic (red) Fourier spectra $(0.2-10 \mathrm{~Hz})$. Contributions from nine super asperities off Miyagi through Ibaraki are considered in the synthetic Fourier spectra. 
Table 4 Sites used to construct the super asperity model

\begin{tabular}{|l|l|l|}
\hline & $\begin{array}{l}\text { Sites where S-wave arrival time was } \\
\text { used to determine the location and } \\
\text { rupture time of the super asperities }\end{array}$ & $\begin{array}{l}\text { Sites where the velocity waveforms and Fourier spectra } \\
\text { were used to determine the parameters of the super } \\
\text { asperities. }\end{array}$ \\
\hline SA1_1 & MYGH12, MYGH06, MYG011 & $\begin{array}{l}\text { MYG001, MYG004, MYGH12, MYGH06, MYG011, } \\
\text { Sendai-G, MYG015, MYGH10, FKS001, FKS004, FKS005 }\end{array}$ \\
\hline SA1_2 & $\begin{array}{l}\text { MYG004, MYGH12, MYG011, Sendai- } \\
\text { GWT008, Ofunato-bochi-G, MYG001, MYG004, MYGH12, } \\
\text { MYG011, Sendai-G }\end{array}$ \\
\hline SA1_3 & IWT007, IWT008, IWT013 & IWT008, Ofunato-bochi-G, MYG001 \\
\hline SA2 & MYGH12, MYGH06, MYG011 & $\begin{array}{l}\text { MYG001, MYG004, MYGH12, MYGH06, MYG011, } \\
\text { Sendai-G, MYG015, MYGH10, FKS001, FKS004, FKS005 }\end{array}$ \\
\hline SA3_1 & FKS006, FKS031, FKS009 & FKS031, FKS009, FKS010, FKS011, Onahama-ji-GB \\
\hline SA3_2 & FKS008, FKS031, FKS009 & FKS031, FKS009, FKS010, FKS011, Onahama-ji-GB \\
\hline SA3_3 & $\begin{array}{l}\text { FKS004, FKS005, FKS006, FKS008, } \\
\text { FKS031, FKS009 }\end{array}$ & $\begin{array}{l}\text { FKS004, FKS005, FKS031, FKS009, FKS010, FKS011, } \\
\text { Onahama-ji-GB }\end{array}$ \\
\hline SA4 & IBR002, IBR003, IBR007 & Onahama-ji-GB, IBR002, IBR003, IBRH18, IBR007 \\
\hline SA5 & IBRH18, IBR007, IBR018, CHBH14 & IBRH18, IBR007, IBR018 \\
\hline
\end{tabular}

however, does not affect the conclusion that "subevents much smaller than conventionally assumed asperities or SMGAs are required to accurately represent the S-wave pulses" even if we assume a terminal rupture velocity ${ }^{23)}$.

The estimated slip on the super asperity ranges from $5.3 \mathrm{~m}$ (SA3_1 and SA3_2) to $42.4 \mathrm{~m}$ (SA2). The estimated slip is also dependent on the rupture velocity assumed. For example, if we assume a rupture velocity 1.5 times greater $(4.5 \mathrm{~km} / \mathrm{s})$, the estimated area of the super asperity will be 2.3 times larger and the estimated slip will be 0.44 times larger. This type of uncertainty, however, does not affect the conclusion that "the amount of slip within a super asperity can be fairly large." The slip on the super asperity proposed by Matsushima and Kawase ${ }^{8)}$ for the 1978 off Miyagi Prefecture earthquake $\left(\mathrm{M}_{\mathrm{w}} 7.6\right)$ was $16.5 \mathrm{~m}$ (they also assumed a rupture velocity of $\left.3.0 \mathrm{~km} / \mathrm{s}\right)$. Thus, the large slip could be a common feature for a super asperity. These observations could provide insights into the physical meaning of the super asperity. Some of the results of waveform inversion conducted for the Tohoku earthquake suggest a large slip region just west of the epicenter ${ }^{24)}$, which is very close to SA2 of this study, although other results suggest a large slip region near the trench axis ${ }^{25}$.

It should be noted that the location of SA1_1 in this study was close to Asperity-1 estimated by Nozu and Sugano ${ }^{26)}$ for the 1978 off Miyagi Prefecture earthquake $\left(\mathrm{M}_{\mathrm{w}} 7.6\right)$ and the super asperity estimated by Matsushima and Kawase ${ }^{8)}$ for the same earthquake (Fig. 3). Additionally, the size of SA1_1 was similar to that of Asperity-1 of Nozu and Sugano ${ }^{26)}$ or the super asperity of Matsushima and $\bar{K}_{\text {awase }}{ }^{8}$. The estimated location and size of the asperity (or the super asperity) for the 1978 earthquake is very reliable, because two independent studies led to a similar result (at least as long as the rupture velocity was reliable). Although there is no specific physical interpretation of a super asperity, it probably corresponds to a locked region in the inter-seismic period. It is then natural to assume that the locked region, which slipped during the 1978 event, was activated again during an earthquake as large as the 2011 Tohoku event. Thus, the rupture of SA1_1 during the 2011 event could be a recurrence of the rupture of a super asperity during the 1978 event. If the above assumption is correct, the size of the super asperity could be specific to the region, rather than dependent on magnitude, which may indicate that it is difficult to establish a scaling relationship for super asperities.

Finally, the question is raised on whether super asperities should be used alone, or combined with asperities (SMGAs) or background regions. As shown in Fig. 14, the synthetic Fourier spectra based on the super asperity model agree fairly well with those observed in the frequency range from 0.2 to $10 \mathrm{~Hz}$. This indicates that a super asperity model can be used alone in this frequency range. In frequencies lower than about $0.2 \mathrm{~Hz}$, however, super asperities should be combined with asperities (SMGAs) or background regions to avoid underestimation. 


\section{CONCLUSIONS}

In this study, a source model composed of super asperities was newly developed for the 2011 off the Pacific coast of Tohoku, Japan, earthquake and strong ground motions were simulated based on site amplification and phase characteristics. The constructed source model involved 9 super asperities, located off the coast of Miyagi through Ibaraki. The agreement between the observed and calculated ground motions was quite satisfactory, especially for the velocity waveforms $(0.2-1.0 \mathrm{~Hz})$ including near-source pulses. In a previous study, the author proposed the following for the evaluation of strong ground motions resulting from a huge subduction earthquake ${ }^{344)}$ :

1) Use a source model composed of relatively small subevents, which is in agreement with the time-width of observed S-wave pulses in the past earthquakes.

2) Calculate strong ground motions based on site amplification and phase characteristics.

The applicability of the above strategy was fully investigated for M8 class earthquakes in a previous study ${ }^{46)}$. The result of this study clearly shows the applicability of the strategy to an M9 earthquake.

Future studies should be conducted to understand the physical meaning of the super asperities and to consider the scaling of super asperities with respect to the size of the entire earthquake for the prediction of strong ground motions.

\section{ACKNOWLEDGMENT}

The author would like to thank the National Research Institute for Earth Science and Disaster Prevention (NIED) for providing important strong motion data. The digital data of the site amplification factors and the computer program used to generate synthetic waveforms in this paper including FORTRAN source code are available to the public ${ }^{6) 15}$.

\section{REFERENCES}

1) Kinoshita, S.: Kyoshin Net (K-net), Seism. Res. Lett, Vol.69, 1998, pp.309-332.

2) Aoi, S., Obara, K., Hori, S., Kasahara, K. and Okada, Y.: New strong-motion observation network: KiK-net, Eos Trans. Am. Geophys. Union, 81, 2000, 329p.

3) Nozu, A.: Prediction of strong ground motions from huge subduction earthquakes in the period range from 1-5 seconds, Prog. and Abst., Seism. Soc. of Jap. 2010, Fall Meeting, B12-04, 2010 (in Japanese).

4) Nozu, A., Nagao, T. and Yamada, M.: Simulation of strong ground motions based on site-specific amplification and phase characteristics, Third Int. Symp. Effects of Surface Geol. on Seism. Motion, Grenoble, France, 2006.

5) Kowada, A., Tai, M., Iwasaki, Y. and Irikura, K.: Evaluation of horizontal and vertical strong ground motions using empirical site-specific amplification and phase characteristics, J. Struct. Constr. Eng., AIJ, No.514, pp.97-104, 1998 (in Japanese with English abstract).

6) Nozu, A. and Sugano, T.: Simulation of strong ground motions based on site-specific amplification and phase characteristics - accounting for causality and multiple nonlinear effects -, Tec. Note of Port and Airport Res. Inst., No.1173, 2008 (in Japanese with English abstract).

7) Nozu, A., Ichii, K. and Sugano, T.: Current status of Strong-Motion Earthquake Observation in Japanese Ports, J. Jap. Assoc. Earthquake Eng., Vol.4, 2004, pp.79-83.

8) Matsushima, S. and Kawase, H.: Source model of a subduction zone earthquake with super-asperity, Chikyu Monthly, Vol.S55, pp.98-102, 2006 (in Japanese).

9) Miyake, H., Iwata, T. and Irikura, K.: Source characterization for broadband ground-motion simulation: kinematic heterogeneous source model and strong motion generation area, Bull. Seism. Soc. Am., Vol.93, 2003, pp.2531-2545.

10) Aki, K.: Scaling law of seismic spectrum, J. Geophys. Res, Vol.71, 1967, pp.1217-1231. 
11) Boore, D.M.: Stochastic simulation of high-frequency ground motions based on seismological models of the radiated spectra, Bull. Seism. Soc. of Am, Vol.73, 1983, pp.1865-1894.

12) Headquaters for Earthquake Research Promotion: Method to evaluate strong ground motions for the anticipated off Miyagi Prefecture earthquake, 2002, http://www.jishin.go.jp/main/kyoshindo/02oct_miyagi1/index.htm

13) Headquaters for Earthquake Research Promotion: Evaluation of strong ground motions for the anticipated off Miyagi Prefecture earthquake (corrected version), 2005, http://www.jishin.go.jp/main/kyoshindo/05dec miyagi/index.htm

14) Satoh, T. and Tatsumi, Y.: Source, path and site effects for crustal and subduction earthquakes inferred from strong motions records in Japan, J. Struct. Constr. Eng., AIJ, No.556, pp.15-24, 2002 (in Japanese with English abstract).

15) Nozu, A. and Nagao, T.: Site amplification factors for strong-motion sites in Japan based on spectral inversion technique, Tec. Note of Port and Airport Res. Inst., No.1102, 2005 (in Japanese with English abstract).

16) Nozu, A. and Wakai, A.: Characteristics of ground motions at damaged ports during the 2011 Great East Japan Earthquake Disaster, Tec. Note of Port and Airport Res. Inst., No.1244, 2011 (in Japanese with English abstract).

17) Nozu, A. and Morikawa, H.: Assessment of soil nonlinearity using empirical Green's function method, Proc. 13WCEE, No.2368, 2004.

18) Kurahashi, S. and Irikura, K.: Source model for generating strong ground motions during the 2011 off the Pacific coast of Tohoku Earthquake, Earth Planets Space, Vol.63, 2011, pp.571-576.

19) Asano, K. and Iwata, T.: Strong ground motion generation during the 2011 off the Pacific coast of Tohoku earthquake revealed by the broadband strong motion simulation, Seism. Soc. of Jap. 2011 Fall Meeting, A11-06, 2011 (in Japanese).

20) Satoh, T.: Source model of the 2011 off the Pacific coast of Tohoku earthquake using empirical Green's function method and scaling law of the source parameters, Seism. Soc. of Jap. 2011 Fall Meeting, B22-04, 2011 (in Japanese).

21) Kawabe, H., Kamae, K. and Uebayashi, H.: Source model of the 2011 Tohoku-chiho Taiheiyo-oki earthquake, Seism. Soc. of Jap. 2011 Fall Meeting, B22-05, 2011 (in Japanese).

22) Kamae, K. and Irikura, K.: Source model of the 1995 Hyogo-ken Nanbu earthquake and simulation of near-source ground motion, Bull. Seism. Soc. of Am, Vol.88, 1998, pp.400-412.

23) Fukuyama, E.: Parameters for earthquake rupture dynamics, Zisin, second series, Vol.61, S309-S314, 2009 (inJapanese with English abstract).

24) Koketsu, K., Yokota, Y., Nishimura, N., Yagi, Y., Miyazaki, S., Satake, K., Fujii, Y., Miyake, H., Yamanaka, Y., Sakai, S. and Okada, T.: A unified source model for the 2011 Tohoku earthquake. Earth Planet. Sci. Lett., Vol.310, 2011, pp.480-487.

25) Suzuki, W., Aoi, S., Sekiguchi, H. and Kunugi, T.: Rupture process of the 2011 Tohoku-Oki mega-thrust earthquake (M9.0) inverted from strong-motion data, Geophys. Res. Lett., Vol.38, 2011, L00G16, doi:10.1029/2011GL049136.

26) Nozu, A. and Sugano, T.: Simulation of strong ground motions from shallow crustal and subduction-zone earthquake based on site-specific amplification and phase characteristics, Technical Note of the Port and Airport Research Institute, No.1120, 2006 (in Japanese with English abstract).

(Original Japanese Paper Published: May, 2012)

(English Version Submitted: October 2, 2014)

(English Version Accepted: November 11, 2014) 